\title{
Waving behaviour of fatigue stress fluctuation in shrink-fit assemblies using 3D finite elements
}

\author{
H. N. Nguyen, V. N. Le, H. Champliaud \& F. Martin \\ Department of Mechanical Engineering, École de technologie supérieure, \\ Montréal, Canada
}

\begin{abstract}
High bearing load roller shafts are made of high performance steels as they are subjected to severe fatigue conditions, which combine a shrink-fit load and a rotating bending. Alternating stress intensity for fatigue analysis under said conditions, using elastic and maximum shear stress theories, shows a waving behaviour within a short distance near the contact edge. This discovery is observed by using structured 3D finite element models with surface-to-surface contact and element sizes varying from a coarse size far from the contact edge down to the order of sliding displacement near the contact edge. These FE models provide proof that stresses near the contact edge increase indefinitely when element size reduces. It is also found that the maximum alternating stress intensity at the depth of one ten-thousandth of the shaft diameter, using the friction coefficient of 0.01 in FE models, gives a good comparison with empirical fatigue data of classic shrink-fit assemblies for a wide range of geometry and loading.
\end{abstract}

Keywords: shrink-fit, rotating bending, fatigue, alternating stress intensity, finite element, singularity, stress concentration factor.

\section{Introduction}

Roller shafts subjected to high bearing loads, such as those supporting rotary kilns in the cement industry shown in figure 1, are usually made of high strength steels for resistance against severe fatigue loading which combines a shrink-fit load and a rotating bending [1].

The only single, widely used, formula for contact pressure between hub and shaft due shrink-fit load is Lamé's formula, shown as formula (1) in the next section, which is analytically developed by using the elastic theory of thick 
walled cylinders subjected to internal and external pressures and assuming either plane stress or plane strain state in the axial direction for both the hub and the shaft [2].

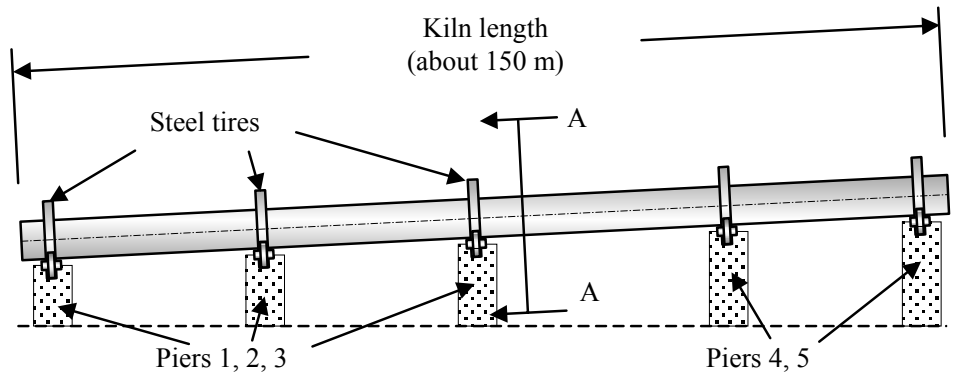

(a) About 3000-tone rotary kiln supported at 5 piers

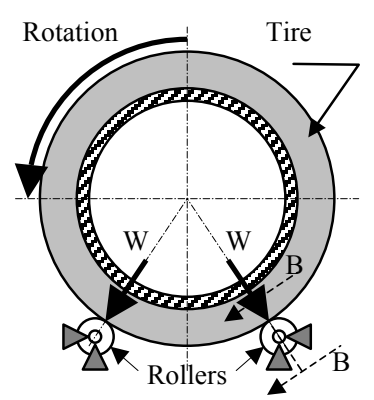

(b) View A-A: Two roller shafts at each pier

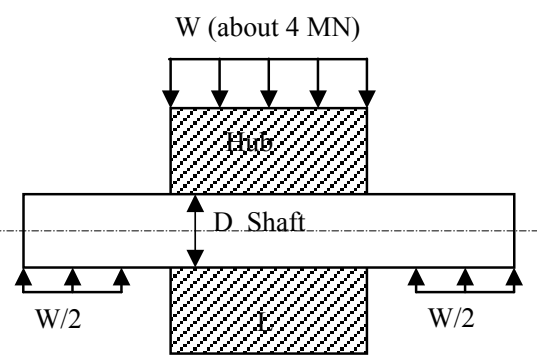

(c) View B-B: Load on each roller shaft

Figure 1: High bearing load roller shafts in cement industries.

In reality, the shaft and the hub having finite lengths with the shaft being longer than the hub, they both exhibit non-zero 3D stress states because neither plane stress nor plane strain state applies. In about 1975, a very tedious analytical procedure, without giving close form formulas, was developed for classic shrink-fit assemblies. It was numerically applied and demonstrated that the contact pressure varies along the contact length, from about Lamé's value in the central region to an indefinitely high value at the contact edge [3]. More recently, stress distribution in the shaft and the hub due to the shrink-fit load could be obtained using axisymmetric finite element models [4, 5] and confirms that the contact edge is a singular region because stresses increase indefinitely there when element size reduces [5].

When shrink-fit assemblies are subjected to rotating bending, the overall stress distribution becomes much more complex and their fatigue life is not obviously evaluated because of the singular behaviour at the contact edge. Fatigue experiments and stress evaluation for shrink-fits and rotating bending have been done since 1936 [6], and a chart for the empirical fatigue stress 
concentration factor of classic shrink-fits has been established based on experimental data [7].

This paper analyses stresses near the contact edge of shrink-fit assemblies subjected to rotating bending using 3D finite element models.

\section{Empirical fatigue stress concentration factor for shrink-fits}

Only classic shrink-fit shafts have a quantitative procedure for fatigue analysis. A shrink-fit assembly is said to be classic if there is no groove and the contact edge is square, such as that shown in figure 1(c). By this procedure, Lamé's pressure $\mathrm{p}$ is calculated using formula (1) shown below, which is developed for shrink-fit pressure between thick walled cylinders using plane stress or plane strain state in the axial direction [1]:

$$
p=\frac{\frac{\Delta D}{D}}{\frac{1}{E_{h}}\left(\frac{D_{o}^{2}+D^{2}}{D_{o}^{2}-D^{2}}\right)+v_{h}+\frac{1}{E_{s}}\left(\frac{D^{2}+D_{i}^{2}}{D^{2}-D_{i}^{2}}\right)-v_{s}}
$$

where dimensions $\mathrm{D}, \mathrm{D}_{\mathrm{o}}, \mathrm{D}_{\mathrm{i}}$, and the diametric interference $\Delta \mathrm{D}$ are shown in figure 2, E and $v$ represent Young's modulus and Poisson's ratio respectively, and the subscripts $h$ and s stand for hub and shaft materials, respectively.

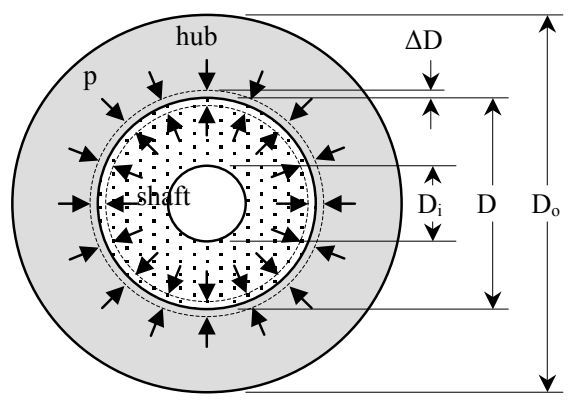

Figure 2: The hub and the shaft considered as thick walled cylinders.

Nominal bending stress in the shaft is also calculated using formula (2) given by strength of material, where $\mathrm{M}$ is the bending moment in the shaft.

$$
\sigma=\frac{32 \mathrm{MD}}{\pi\left(\mathrm{D}^{4}-\mathrm{D}_{\mathrm{i}}{ }^{4}\right)}
$$

Fatigue stress concentration factor $\mathrm{K}_{\mathrm{t}}$ is obtained using an empirical chart reproduced in figure 3 [7], which is based on experimental fatigue data of classic shrink-fits in function of two ratios: ratio L/D between the hub length and the 
shaft diameter, and ratio $\mathrm{p} / \sigma$ between Lamé's pressure and nominal bending stress in the shaft. The alternating stress $\mathrm{S}_{\mathrm{a}}$ is finally calculated by formula (3) and input to a proper fatigue curve $(\mathrm{S}-\mathrm{N})$ of shaft material for predicting the life of the shaft.

$$
\mathrm{S}_{\mathrm{a}}=\mathrm{K}_{\mathrm{t}} \sigma
$$

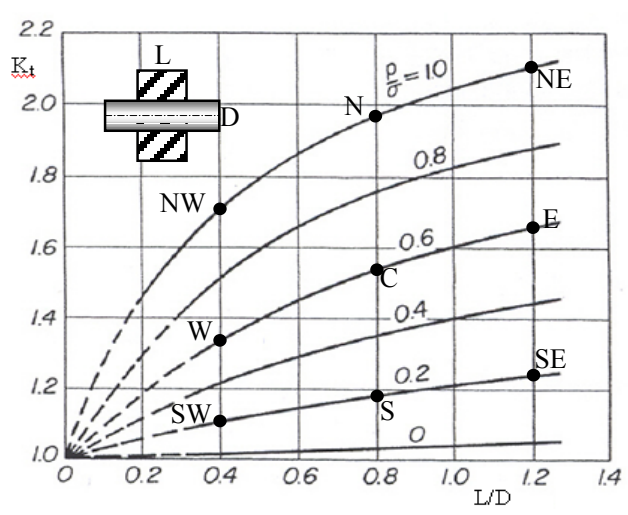

Figure 3: Empirical fatigue stress concentration factor for classic shrink-fits [7].

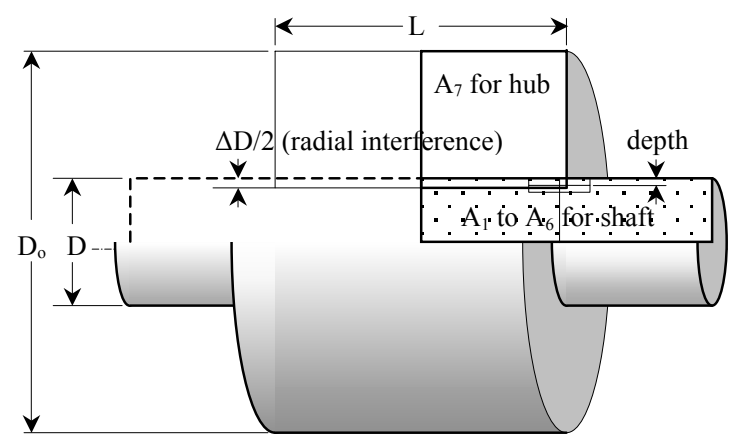

Figure 4: $\quad$ Surfaces for the shaft and the hub in a radial plane of the half shrink-fit assembly.

\section{Finite element (FE) model}

Since the hub and shaft assembly has two symmetry planes, only $1 / 4$ of the assembly is studied in the present paper using ANSYS finite element Code [8]. Seven surfaces for a radial section of the half shaft and the hub are first created as shown in figure 4 , where $\Delta \mathrm{D} / 2$ is radial interference, and $\mathrm{d}$ is a small depth from the shaft surface near the contact edge. A key line at a small depth d allows 
for accurate examination of stress distribution near the contact edge because stresses quickly vary within short distances around this edge, [3]. These surfaces are temporarily meshed into 4-node flat elements with controlled sizes, a coarse size far from the contact edge, and a very fine size near the contact edge as shown in figure 5. These flat elements are used for generating 3D solid 8-node elements by using extrusion and volume rotation options (EXTOPT and VROTATE commands). This mesh technique gives a relatively small number of nodes (about 20000 to 50000 nodes) with reliable results near the contact edge.

Figure 6 shows the resulting 3D element mesh for $1 / 4$ of a classic shrink-fit assembly.
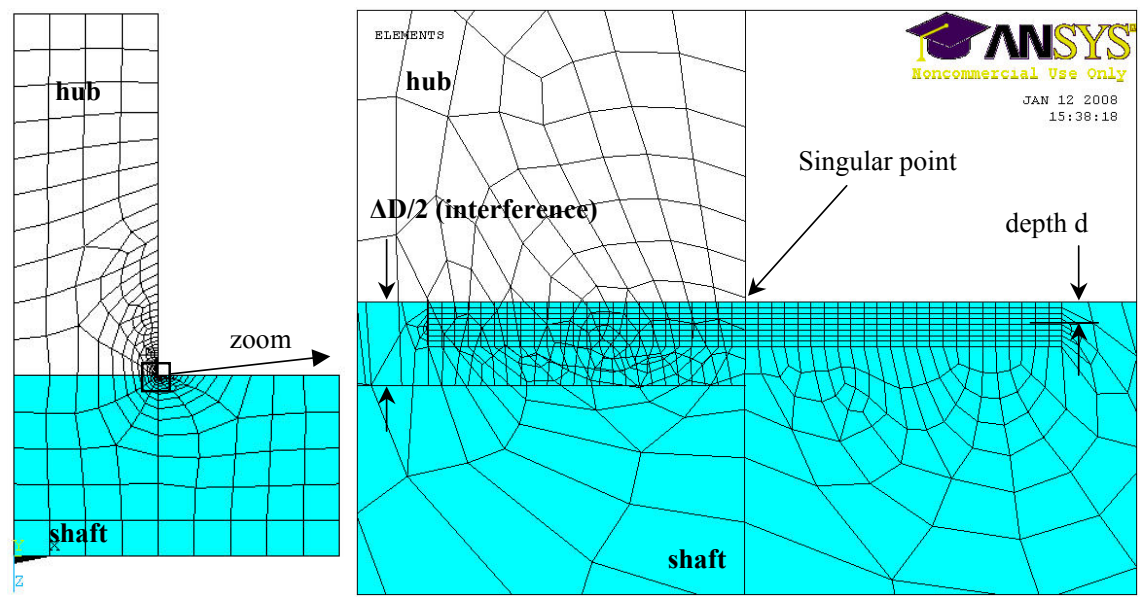

Figure 5: Generator flat element mesh in a radial plane.

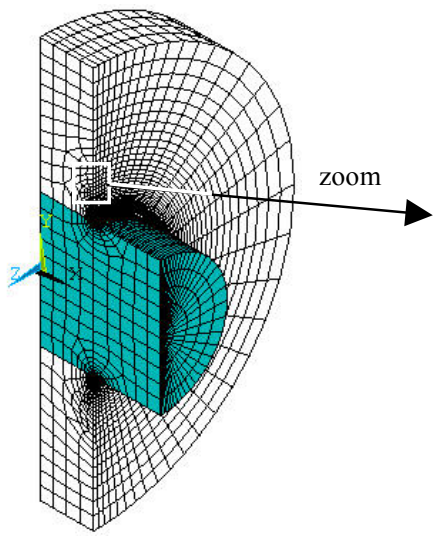

a) $1 / 4 \mathrm{FE}$ model

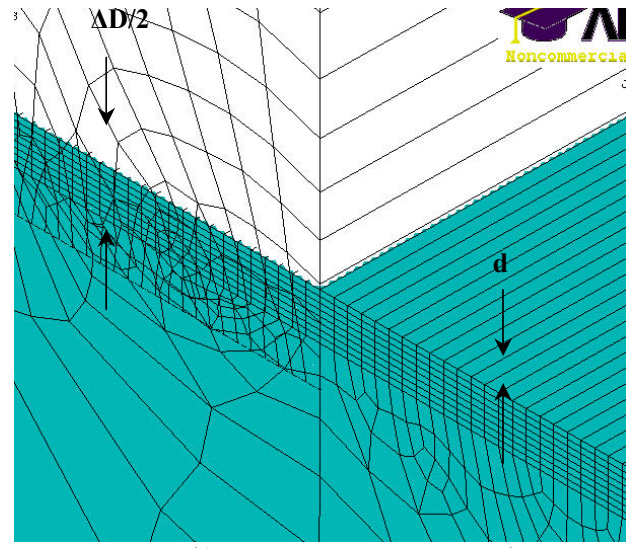

b) Zoom near top contact edge

Figure 6: A quarter finite element model for a classic shrink-fit. 
The following boundary conditions are applied to the FE model:

1. Surface-to-surface target and contact elements covering the nodes on the inside diameter of the hub and nodes on the outside diameter of shaft;

2. Symmetry conditions for nodes on the symmetry planes (XY and YZ); and

3. Bending moment replaced by linearly variable pressure at the nodes on the end section of the shaft, equivalent to formula for nominal bending stress.

\section{FE results}

Nine classic shrink-fit cases, shown in figure 3 by letters $C, E, W, S, N$ (for Center, East, West, etc), are studied in order to find a depth d from the shaft surface where FE results give comparable fatigue stress results with the empirical fatigue procedure mentioned in section 2. The following parameters are fixed for all cases: $D_{i}=0, D_{o} / D=3$ (hub 3 times bigger than shaft), the same elastic material properties for the hub and the shaft, and interference $\Delta D / D=$ 0.00075 . The Lamé's pressure for all these cases is $\mathrm{p}=0.3333^{*} \mathrm{E} / 1000$ according to formula (1).

\subsection{Stresses due to shrink-fit alone}

Without a bending moment, a typical radial stress contour plot for a $3 \mathrm{D} \mathrm{FE}$ model due to shrink-fit loading alone is shown in figure 7 . These results are practically identical with those given by $2 \mathrm{D}$ axisymmetric models [5]: values in the central region of the contact interface are approximately equal to Lamé's pressure calculated by formula (1); radial stress at the contact edge increases indefinitely when element size is reduced. It is noticed that element size near the contact edge is in the order of $0.6 \mathrm{D} / 10000$.
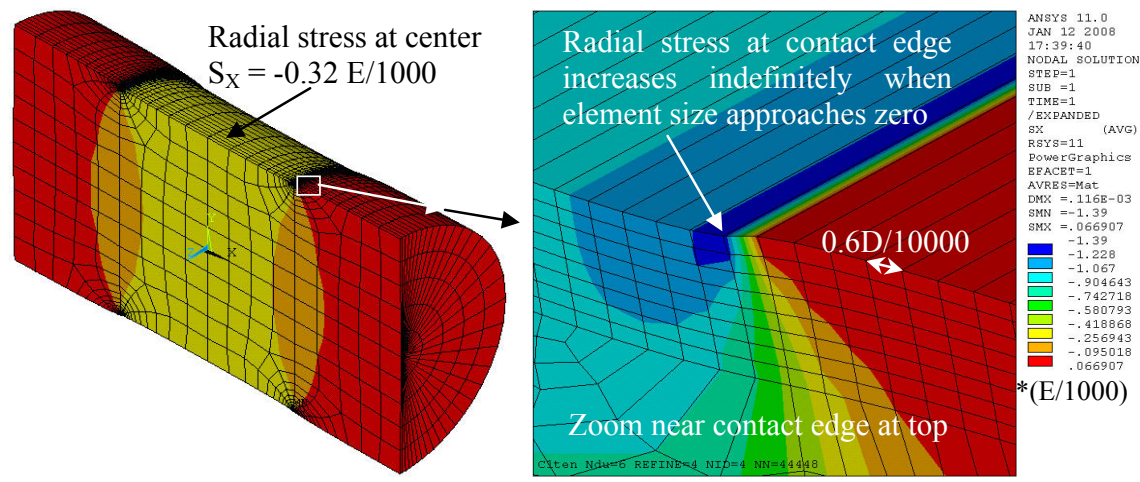

Figure 7: Radial stress distribution in the shaft due to shrink-fit alone for case $\mathrm{C}$. 


\subsection{Stresses due to shrink-fit plus bending}

When a shrink-fit assembly is subjected to a bending, the shaft slightly shortens when at the top and stretches when at the bottom, so that small axial sliding occurs at the edges: the shaft slides in at the top and slides out at the bottom, as shown in figure 8 . Since stresses quickly change within a very short distance near the contact edge, the element size in this region needs be refined to the order of the sliding displacement, for example, the sliding displacements at the edges for case $\mathrm{C}(\mathrm{L} / \mathrm{D}=0.8, \mathrm{p} / \sigma=0.6)$ is about $2.4 \mathrm{D} / 10000$, and the element size around edges is about $0.6 \mathrm{D} / 10000$.

Stresses are examined at several nodes $\mathrm{P}$ in the shaft near the contact edge, each node axially moving in and out when at the top and the bottom; see $\mathrm{P}_{\mathrm{t}}$ and $\mathrm{P}_{\mathrm{b}}$ in figure 8 .

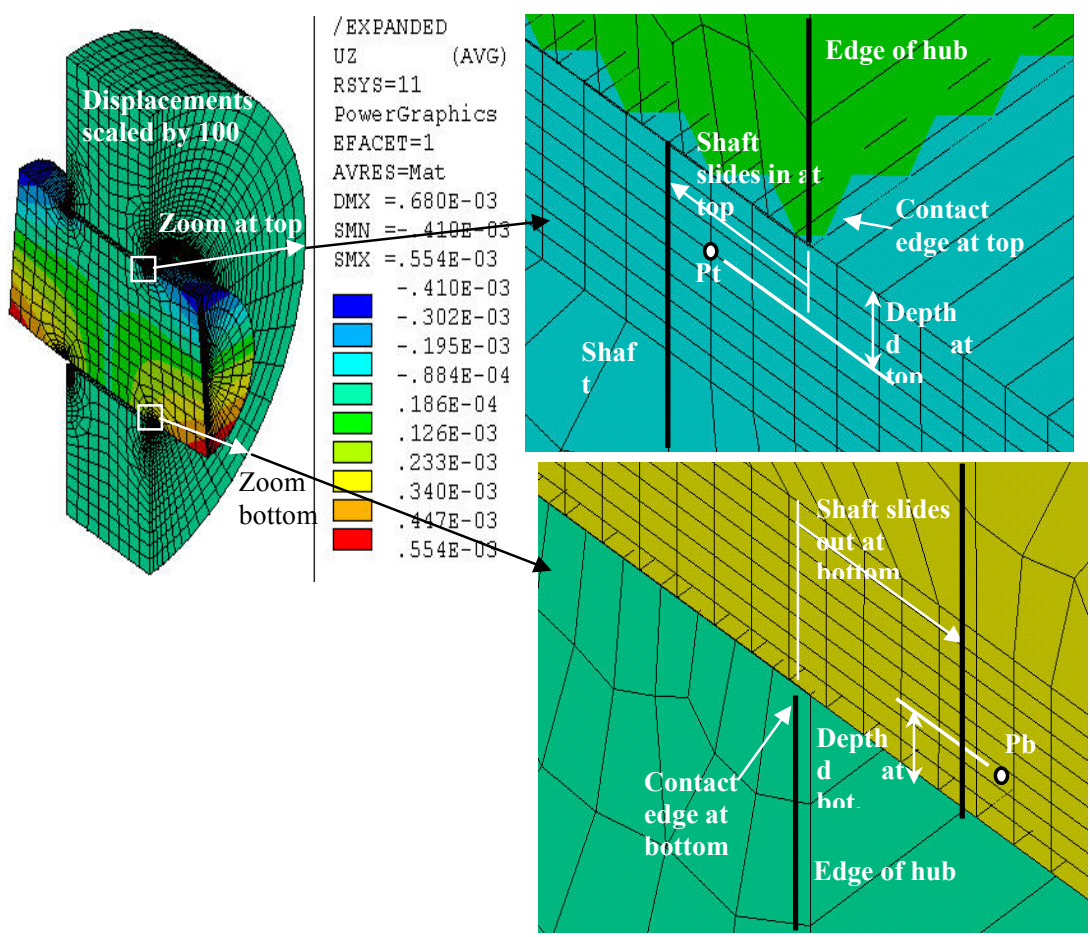

Figure 8: Axial sliding near contact edge at the top and bottom due to bending for case $\mathrm{C}(\mathrm{L} / \mathrm{D}=0.8, \mathrm{p} / \sigma=0.6)$.

\subsubsection{Alternating tresses in the shaft at various depths $d$ near the contact edge}

The stress ranges for stress components at a point $\mathrm{P}$ are calculated as follows:

- Radial stress range: $\Delta \sigma_{R}=\sigma_{R}\left(\right.$ point $\left.P_{b}\right)-\sigma_{R}\left(\right.$ point $\left.P_{t}\right)$

- Axial stress range: $\Delta \sigma_{\mathrm{Z}}=\sigma_{\mathrm{Z}}\left(\right.$ point $\left.\mathrm{P}_{\mathrm{b}}\right)-\sigma_{\mathrm{Z}}\left(\right.$ point $\left.\mathrm{P}_{\mathrm{t}}\right)$

- Shear stress range: $\Delta \tau_{\mathrm{RZ}}=\tau_{\mathrm{RZ}}\left(\right.$ point $\left.\mathrm{P}_{\mathrm{b}}\right)-\tau_{\mathrm{RZ}}\left(\right.$ point $\left.\mathrm{P}_{\mathrm{t}}\right)$

- Hoop stress range: $\Delta \sigma_{\theta}=\sigma_{\theta}\left(\right.$ point $\left.\mathrm{P}_{\mathrm{b}}\right)-\sigma_{\theta}\left(\right.$ point $\left.\mathrm{P}_{\mathrm{t}}\right)$ 
The principal stress ranges at point $\mathrm{P}$ are computed as follows

$$
\begin{gathered}
\Delta \sigma_{1}=\frac{\Delta \sigma_{\mathrm{R}}+\Delta \sigma_{\mathrm{Z}}}{2}+\sqrt{\left(\frac{\Delta \sigma_{\mathrm{R}}-\Delta \sigma_{\mathrm{Z}}}{2}\right)^{2}+\Delta \sigma_{\mathrm{RZ}}{ }^{2}} \\
\Delta \sigma_{2}=\frac{\Delta \sigma_{\mathrm{R}}+\Delta \sigma_{\mathrm{Z}}}{2}-\sqrt{\left(\frac{\Delta \sigma_{\mathrm{R}}-\Delta \sigma_{\mathrm{Z}}}{2}\right)^{2}+\Delta \sigma_{\mathrm{RZ}}{ }^{2}} \\
\Delta \sigma_{3}=\Delta \sigma_{\theta}
\end{gathered}
$$

The alternating stress intensity, using maximum shear stress criteria, is:

$$
\mathrm{S}_{\mathrm{a}}=\frac{\Delta \sigma_{\max }-\Delta \sigma_{\text {min }}}{2}
$$

$\Delta \sigma_{\max }$ and $\Delta \sigma_{\min }$ being the maximum and minimum of $\left[\Delta \sigma_{1}, \Delta \sigma_{2}, \Delta \sigma_{3}\right]$.

Figure 9 shows the distributions of alternating stress intensity $\mathrm{S}_{\mathrm{a}}$ in shaft within a short distance along the axial direction near the contact edge at seven different depths $\mathrm{d}$ and figure 10 shows the variation tendency of maximum values of $\mathrm{S}_{\mathrm{a}}\left(\mathrm{S}_{\mathrm{a} \text { max }}\right)$ in the function of depth. It is found that, due to sliding in and out near the contact edge, (1) $\mathrm{S}_{\mathrm{a}}$ has waving variations within a distance of about four times the sliding displacement; (2) maximum alternating stress intensity $\left(\mathrm{S}_{\mathrm{a}}\right.$ max) occurs outside the contact edge by a distance greater than the sliding displacement; and (3) $\mathrm{S}_{\mathrm{a} \text { max }}$ tends to infinity when the depth approaches zero.

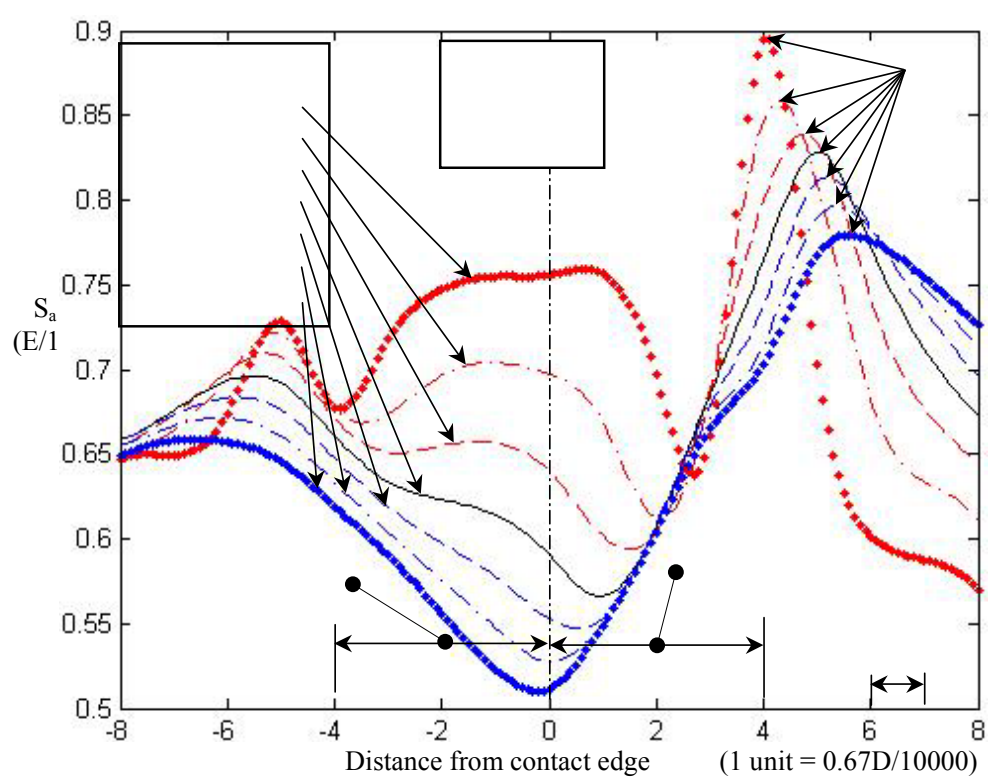

Figure 9: Distributions of alternating stress intensity $\left(\mathrm{S}_{\mathrm{a}}\right)$ in the shaft along the axial direction near the contact edge at different depths. 


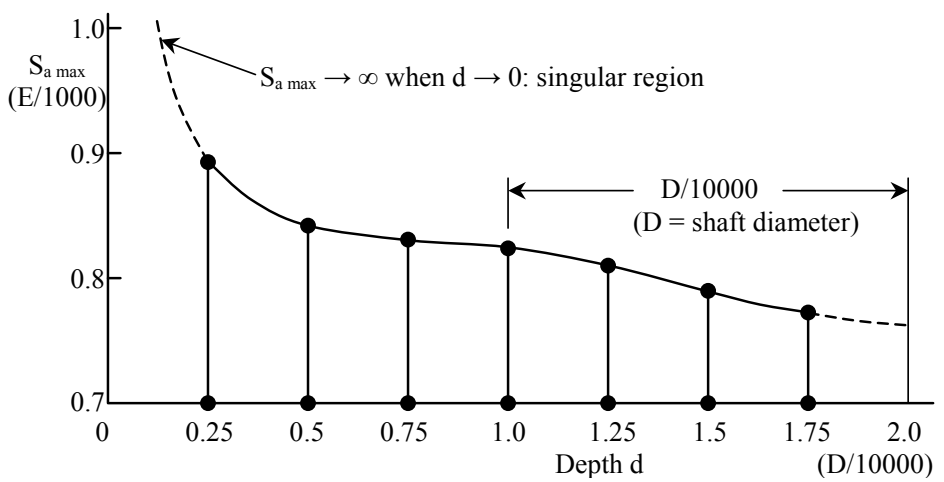

Figure 10: Variation tendency of maximum $S_{a}$ in function of depth near contact edge.

\subsubsection{Effect of friction on alternating stresses}

FE results shown in the previous sections are for zero friction. The same FE models can be used with any input friction coefficient for target and contact elements. The maximum alternating stress intensity at a depth of $\mathrm{D} / 10000$ varies with the friction coefficient as shown in figure 11. These results show that the friction coefficient would have a negative effect on fatigue stress in shrink-fit shafts.

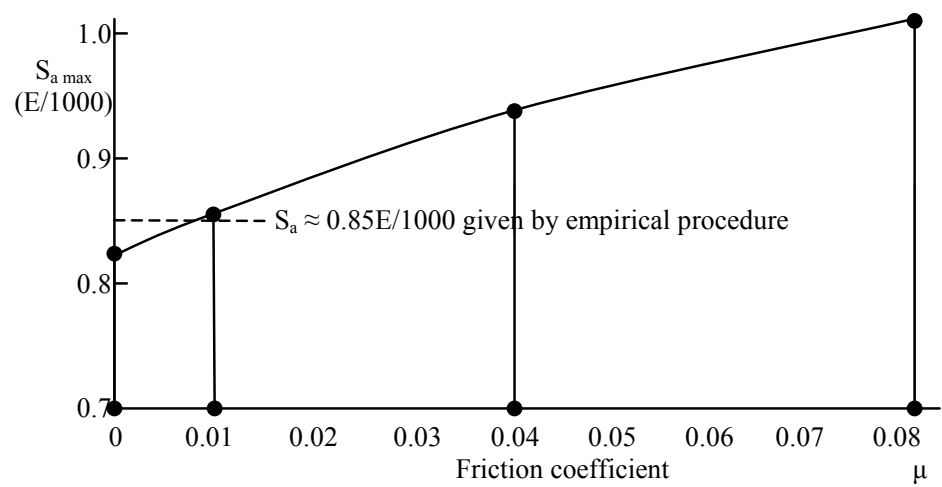

Figure 11: Variation of $S_{a \max }$ at depth $D / 10000$ in the function of the friction coefficient.

\subsubsection{Using FE results for fatigue analysis of a shrink-fit shaft}

Since FE elastic analysis stresses do not converge to stable values for nodes on the surface of the shaft near the contact edge when the element size is reduced, and since fatigue stresses significantly depend on the friction coefficient, it is suggested using a combination of a certain friction coefficient $\mu$ and maximum alternating stress intensity at a certain depth $\mathrm{d}$ so as to give comparable fatigue life prediction with the empirical fatigue procedure previously mentioned in section 2. 
For example, for $\mathrm{L} / \mathrm{D}=0.8$, Lamé's pressure $\mathrm{p}=0.3333 \mathrm{E} / 1000$ and nominal bending stress $\sigma=0.5555 \mathrm{E} / 1000$ (case $\mathrm{C}$ ), the empirical fatigue procedure uses the chart in figure 3 to give a fatigue stress concentration factor of about $\mathrm{K}_{\mathrm{t}} \approx$ 1.53 and thus an alternating stress of $\mathrm{S}_{\mathrm{a}}=\mathrm{K}_{\mathrm{t}} \sigma \approx 0.85 \mathrm{E} / 1000$.

The FE results in figure 11 show that using a friction coefficient $\mu=0.01$ in conjunction with depth $\mathrm{d}=\mathrm{D} / 10000$ would agree well with the empirical result $\mathrm{S}_{\mathrm{a}}=0.85 / 1000$ for case $\mathrm{C}$. By studying the nine cases shown in figure 3 by letters $\mathrm{C}, \mathrm{E}, \mathrm{W}, \mathrm{S}$ and $\mathrm{N}$, the results for maximum alternating stress intensity at depth $\mathrm{D} / 10000$ are summarized in table 1 in comparison with values given by the empirical fatigue procedure in [7]. Both FE and empirical results together agree well with less than an $11 \%$ difference for a wide range of geometry and loading.

Table 1: $\quad S_{a \max } /(E / 1000)$ for nine studied cases of classic shrink-fits (shaft diameter $\mathrm{D}$, hub length $\mathrm{L}$, Lamé's pressure $\mathrm{p}$, nominal bending stress $\sigma$ ).

\begin{tabular}{|r|c|c|c|c|c|c|}
\hline $\mathrm{L} / \mathrm{D}$ & \multicolumn{2}{|c|}{0.4} & \multicolumn{2}{c|}{0.8} & \multicolumn{2}{c|}{1.2} \\
\hline $\mathrm{p} / \sigma \downarrow$ & $\mathrm{S}_{\mathrm{a} \text { F.E. }}$ & $\mathrm{S}_{\mathrm{a}}[7]$ & $\mathrm{S}_{\text {a F.E. }}$ & $\mathrm{S}_{\mathrm{a}}[7]$ & $\mathrm{S}_{\mathrm{a} \text { F.E. }}$ & $\mathrm{S}_{\mathrm{a}}[7]$ \\
\hline 1.0 & $0.50(12 \%)$ & 0.57 & $0.60(8 \%)$ & 0.65 & $0.63(10 \%)$ & 0.70 \\
\hline 0.6 & $0.75(1 \%)$ & 0.74 & $0.86(1 \%)$ & 0.85 & $0.89(3 \%)$ & 0.92 \\
\hline 0.2 & $1.98(7 \%)$ & 1.85 & $2.16(9 \%)$ & 1.97 & $2.30(11 \%)$ & 2.07 \\
\hline
\end{tabular}

\section{Conclusion}

- $\quad 3 \mathrm{D}$ elastic FE analysis shows that stresses due to shrink-fit and bending are singular at the contact edge, i.e. increase indefinitely when element size reduces.

- Alternating stresses in the shrink-fit shaft have a waving variation along the axial direction in a short distance of about twice the sliding displacement at the edge.

- The maximum alternating stress intensity in a classic shrink-fit shaft at a depth of one ten thousandth of the shaft diameter (D/10000), given by 3D surface-to-surface contact FE models with a friction coefficient of 0.01 agree well with values given by the empirical fatigue procedure for a wide range of cases.

- The advantage of using FE results for the fatigue analysis of shrink-fit shafts is that they can be applied to a shrink-fit assembly with any geometry such as those with a grooved hub and shaft, while the empirical fatigue procedure is established for classic shrink-fit assemblies only.

\section{References}

[1] V.N. Le, Comparative Fatigue Analysis of Shaft-Roller Designs for Bath Kiln, ETS-CTS-2005-08-01 Report, Lafarge CTS, Montreal, 2005. 
[2] J.E. Shigley, C.R. Mischke, Richard G. Budynas, Mechanical Engineering Design, McGraw Hill, 2004.

[3] G.P. Steven, The Shrink-Fit Problem with Both Components Being Elastic, Int. J. of Engng Sci., Vol. 13, 1975.

[4] A. Özel, S. Temiz, M.D. Aydin, S. Şen, Stress analysis of shrink-fit joints for various fit forms via finite element, Materials and design, 26(4), p.281289, 2005.

[5] F. Martin, V.N. Le, H. Champliaud, H.N. Nguyen, Stress Concentration of Shrink Fit Assembly Using Finite Element Method, The IASTED Asian Conference on Modeling and Simulation, Beijing, October 8-10, 2007.

[6] R.E. Peterson, A.M. Wahl, Fatigue of Shafts at Fit Members With a Related Photoelastic Analysis, Journal of Applied Mechanics, vol.58, 1936.

[7] M.F. Spotts, Design of Machine Elements, Prentice-Hall, ISBN 0-13726167-5, 1998.

[8] ANSYS 11, Engineering Simulation Solution, www.ansys.com, 2007 